\section{Dounreay loses uranium}

\section{London}

ONE of the two nuclear waste reprocessing facilities at the UK Atomic Energy Authority (AEA)'s plant in Dounreay, Scotland, has been shut down after plant managers found that they cannot account for

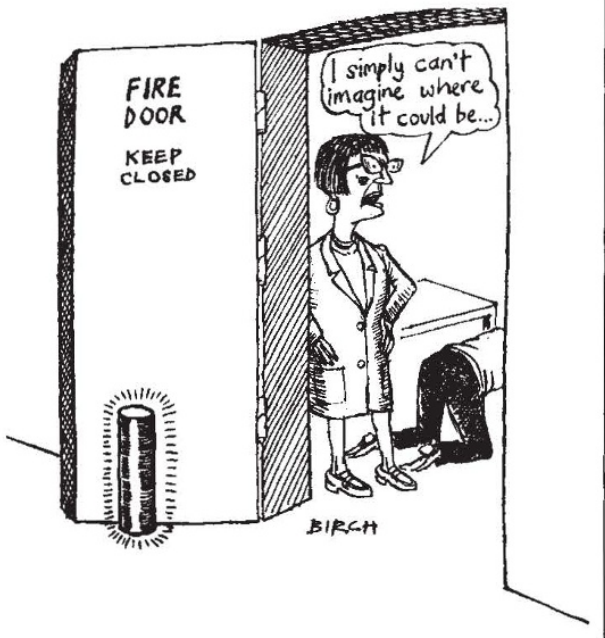

some $10 \mathrm{~kg}$ of enriched uranium. The discrepancy may be simply due to an error in accounting - no leaks of radioactive material have been detected, and plant security should prevent anyone removing uranium from the site - but the revelation is highly embarrassing for AEA. Enriched uranium can be used in weapons production, and the 'loss' of a substantial quantity emerged last week at a time when inspectors from Euratom, the European Atomic Energy Community, were visiting Dounreay.

The plant handles spent fuel from AEA's prototype fast reactor, also at Dounreay, and provides a commercial reprocessing service for a number of smaller research reactors. Because of the difficulty in measuring precisely the quantity of uranium passing through the plant, AEA assumes that no uranium has been lost if the quantity measured after reprocessing is within 2 per cent of the amount that should be present. For security reasons, AEA will not reveal the amount by which the unaccounted $10 \mathrm{~kg}$ of uranium exceeds this margin of error, but a spokesman says the discrepancy is "much larger" than that usually allowed.

The offending section of the plant will remain closed until a team from AEA's London headquarters, led by nuclear materials accountancy expert Wyn Llewelyn, has solved the mystery of the missing uranium. AEA promises a public report once Llewelyn's findings are known.

Peter Aldhous

\section{Misconduct increases at NSF}

\section{Washington}

SCIENTIFIC misconduct cases being investigated by the National Science Foundation (NSF) have risen more than 16-fold in the past two years, the agency's inspector general reported last week. At the end of 1989 , NSF was investigating three misconduct cases; it now has 49 cases in progress and has been forced to add more staff to work exclusively on misconduct.

Two of the most serious cases highlighted in the inspector general's report involve plagiarism, a charge that is "very common among the misconduct cases we receive", the report says.

In one of the cases, a researcher in the electrical engineering department of a "large midwestern university" (NSF did not identify the parties in any of the cases) copied extensively from two other researchers when preparing his grant applications. Responding to a university investigative panel, the researcher claimed that although he might have "mistakenly" copied text from two papers, his proposed methods were novel. But after inspecting the works, the panel concluded that the researcher's "unique contribution" was "linking one source's introduction and definition of the problem to another source's presentation of the method of solution." The inspector general recommended that the researcher be barred from receiving federal funding for three years.

In the other case, an agricultural researcher in a "small southern university" copied the section on research methods in his NSF grant application from another paper. Again, when challenged, the researcher used a 'carelessness defense'. The university investigative panel accepted the excuse and concluded that the researcher had "seriously deviated from accepted practices", but had not committed plagiarism.

This defence, the NSF report argues, is a red herring, but an increasingly common one. "We have found that questions about the subject's intent frequently arise in inquiries and ... often introduce confusion." NSF takes the position that by signing grant applications, researchers take responsibility for any plagiarism found in them, regardless of intent. "Inquiries into the state of mind of those researchers are beside the point in situations where express certification is provided," the NSF report concludes. In this case, the inspector general disagreed with the university investigative panel, found plagiarism, and recommended a two-year debarment.

Christopher Anderson

\section{Logjam ahead for UK academics}

\section{London}

THE average Mexican academic has better access to supercomputers than his counterpart in Britain, according to a new report from the Parliamentary Office of Science and Technology (POST), the fledgling British answer to the US Congress's Office of Technology Assessment. Although in 1985 Britain's academic supercomputing facilities compared favourably with those in other developed countries, British investment has since lagged far behind that in the United States, Germany, Japan and Canada.

POST warns that the three British academic supercomputing centres - at the Science and Engineering Research Council's Rutherford Appleton Laboratory, and in university centres at London and Manchester - are already fully occupied, and that the Natural Environment Research Council (NERC)'s planned work on ocean and atmospheric circulation modelling will soon overwhelm the system. The dearth of supercomputers also brings a commercial penalty: British academics are increasingly turning to supercomputing centres in the United States, where they must make their results available to all US researchers. POST notes that results from UK government-funded research at University College London and the University of Swansea are now freely available to US aerospace companies.

If the projected supercomputing needs of British academics are to be met, the POST report says, then the government will have to spend substantially more than the extra $£ 10$ million it plans for academic supercomputing over the next two years. Providing NERC with its own machine, costing around $£ 6$ million, may be one answer to the problem, according to POST.

But costs could be cut by allowing academic researchers to work on the halfdozen supercomputers in Britain's defence research laboratories and the Cray-2 machine at the UK Atomic Energy Authority (AEA)'s Harwell laboratory. These are thought to have enough spare capacity to add a third to Britain's academic supercomputing capacity, but there are obstacles to their use for academic research projects. Michael Schomberg, computing manager at Harwell, explains that AEA is given rigid profit targets by the Department of Energy, and cannot allow academics free use of Harwell's machine. Nevertheless, Schomberg believes it should be possible for the Department of Education and Science to negotiate with the Ministry of Defence and the Department of Energy to find a way to improve academic supercomputing provision at a cheaper cost than buying new machines.

Peter Aldhous 